\title{
AFRICAN AMERICANS SHOW ALTERATIONS IN ENDOGENOUS PAIN REGULATORY MECHANISMS AND REDUCED PAIN TOLERANCE TO EXPERIMENTAL PAIN PROCEDURES
}

\author{
Beth Mechlin
}

A thesis submitted to the faculty of the University of North Carolina at Chapel Hill in partial fulfillment of the requirements for the degree of Master of Arts in the Department of Psychology (Biological Psychology).

Chapel Hill

2006

Approved by

Advisor: Susan S. Girdler, Ph.D.

Reader: Mark H. Hollins, Ph.D.

Reader: Mitchell J. Picker, Ph.D. 


\begin{abstract}
BETH MECHLIN: African Americans Show Alterations in Endogenous Pain Regulatory Mechanisms and Reduced Pain Tolerance to Experimental Pain Procedures (Under the direction of Susan S. Girdler)

In order to examine ethnic differences in pain sensitivity 51 African Americans (24 men, 27 women) and 55 individuals from Other ethnic groups (primarily Caucasian; 26 men, 29 women) were tested for pain sensitivity to ischemia, heat, and cold pressor tests after both mental stress and rest. Resting and stress-induced blood pressure (BP), plasma norepinephrine (NE), and cortisol were assessed. African Americans had lower pain tolerance relative to Caucasian/Others for all pain tests. Only the Caucasian/Other group showed the expected inverse relationship between BP and pain sensitivity. African Americans exhibited lower cortisol concentrations overall and blunted NE and systolic BP responses to stress. Only in Caucasians/Others was the relationship seen between higher stress-induced BP, cortisol, and NE levels and greater pain tolerance. The results suggest that there are alterations in endogenous pain regulatory mechanisms in African Americans, which may contribute to their greater rate of clinical pain symptoms.
\end{abstract}




\section{ACKNOWLEDGEMENTS}

First, and foremost, I must acknowledge with deepest gratitude, my advisor, Dr. Susan S. Girdler for her guidance, wisdom, mentorship, and motivation. Thank you also to Dr. Mark Hollins and Dr. Mitchell J. Picker for supporting my research endeavors by serving on my thesis committee. I also must express my gratitude to Miss Rebecca Klatzkin, Miss Dot Faulkner, and Miss Chihiro Christmas for the multitude of ways in which they have aided in the conducting and discussion of these findings. I would not have been able to do this without all of the help these people have given me. 
TABLE OF CONTENTS

Page

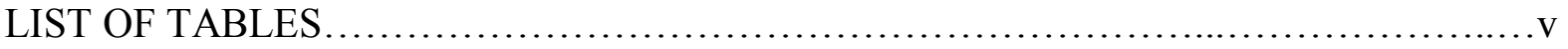

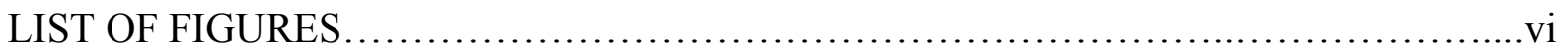

LIST OF ABBREVIATIONS.................................................... vii

Chapter

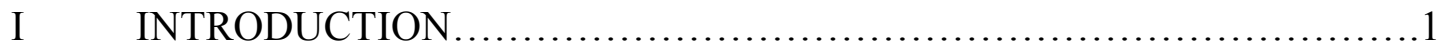

II $\quad$ METHODS ................................................................

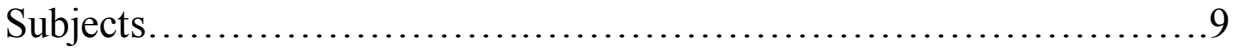

Procedures............................................................ 10

Data Reduction and Analysis.......................................15

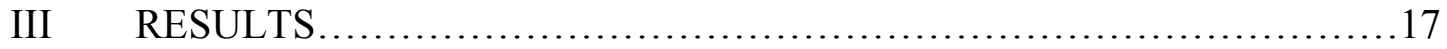

Demographic and Baseline Characteristics.......................17

Effects of Ethnicity on Pain Sensitivity..............................18

Cardiovascular and Neuroendocrine Reactivity to Stress................19

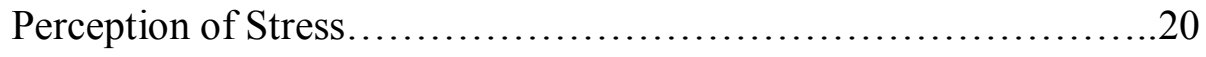

Relationship of Physiological Variables to Pain Sensitivity...........21

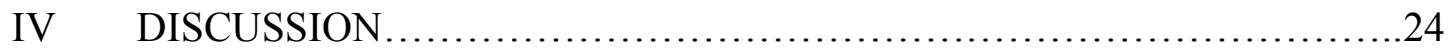

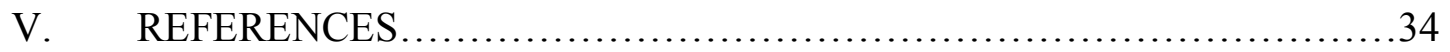




\section{LIST OF TABLES}

Table

1. Mean ( \pm SEM) Demographic and Baseline Characteristics as a Function of

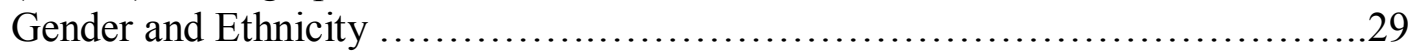

2. Correlations between Pain Tolerance and Physiological Variables......................30 


\section{LIST OF FIGURES}

Figure

1. Ischemic Pain Sensitivity....................................................... 31

(a) After Rest

(b) After Stress

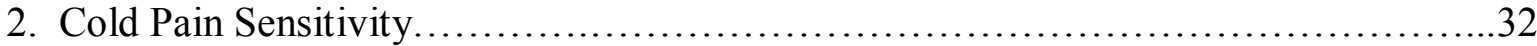

(a) After Rest

(b) After Stress

3. Thermal Pain Sensitivity
(a) After Rest
(b) After Stress 


\section{LIST OF ABBREVIATIONS}

$\begin{array}{ll}\text { ANOVA } & \text { Analysis of Variance } \\ \text { BP } & \text { Blood Pressure } \\ \text { HPA } & \text { Hypothalamic-Pituitary-Adrenocortical } \\ \text { LC } & \text { Locus Coeruleus } \\ \text { NE } & \text { Norepinephrine } \\ \text { SIA } & \text { Stress-Induced Analgesia } \\ \text { SBP } & \text { Systolic Blood Pressure } \\ \text { TSST } & \text { Trier Social Stress Test }\end{array}$




\section{CHAPTER I \\ INTRODUCTION}

African Americans experience more clinical pain (1-3) and report more pain associated with chronic medical conditions such as AIDS, glaucoma, and arthritis (4) relative to Caucasians. For example, using the Multidimensional Pain Inventory and the McGill Pain Questionnaire as measures of pain severity, and examining the amount of time it took participants to walk 100 yards, as well as responses on pain questionnaires to measure pain-related disability, Edwards et al. (1) found that among individuals with a variety of chronic pain conditions, African Americans reported greater perceived pain severity and greater pain-related disability than did Whites. Similarly, McCracken et al. (2) administered questionnaires to Blacks and Whites receiving treatment for chronic pain. The results of their study indicated that Blacks rated their pain as more severe than did Whites. Additionally, Blacks endorsed more avoidance of pain and activity, fearful thinking about pain, and pain-related anxiety. On the other hand, Riley et al. (3) did not find any ethnic difference in ratings of pain intensity among chronic pain patients, which may be due to their measurement of pain intensity as separate from pain unpleasantness, since they did find that African Americans reported their pain as more unpleasant than Whites. Taken together, the available evidence indicates that African Americans experience more clinical pain than Whites for a variety of chronic pain conditions. Additionally, African Americans report higher levels of pain associated with AIDS, 
glaucoma, arthritis, low back pain, and temporomandibular disorders (4). Studies have demonstrated that experimental pain may be predictive of clinical pain since inverse relationships exist between ischemic pain tolerance in the laboratory and reported clinical pain severity among chronic pain populations $(1,5)$. Moreover, a recent longitudinal study showed that in initially pain free females, increased sensitivity to a thermal heat stimulus was a significant predictor for the onset of temporomandibular jaw disorders 3 years later (6). Therefore, studies comparing African Americans with other ethnic groups during experimental pain stimuli may help to clarify the nature of ethnic differences in clinical pain.

Since laboratory-assessed pain sensitivity has been shown to be predictive of clinical pain $(1,5,6)$, studies comparing African Americans with other ethnic groups for sensitivity to experimental pain stimuli may help to clarify the nature of ethnic differences in the clinical pain experience. In the laboratory, most studies indicate no ethnic differences in pain onset (i.e. pain threshold) but that African Americans have reduced pain tolerance relative to primarily Caucasian samples in response to thermal heat pain (7-9), cold pressor pain (7), ischemic pain (7), and pressure pain (10). A study by Sheffield et al. (11) also indicated that when a thermal heat stimulus of a particular degree was applied to the forearm of participants, African Americans rated the pain from the stimulus as more intense and more unpleasant than did Caucasians. While many studies have indicated these ethnic differences in pain perception, it is still unclear why these differences exist.

Only a small handful of studies have examined biological mechanisms that may contribute to these ethnic differences in pain sensitivity. There is a well-established 
literature showing that higher blood pressure is associated with higher pain tolerance (eg. 12-17). For example, Zamir and Shuber (13) tested normotensive and hypertensive males for sensitivity to tooth pulp stimulation. Results indicated that pain thresholds were higher in the hypertensive group than in the normotensive group. Additionally, even when the subjects were divided into groups of younger adults and older adults instead of by hypertensive status, there were significant positive correlations between pain thresholds and blood pressure in both groups. These results extend to normotensive individuals as well since Sheps et al. (14) found that when thermal heat pain was applied to the forearm, pain thresholds and pain tolerance were significantly related to mean arterial pressure in both normotensive and hypertensive subjects. In a study by Bruehl et al. (15) there was a significant correlation between systolic blood pressure and the pain rating of pressure applied to the middle finger in normotensives. McCubbin and Bruehl (16) examined relationships between blood pressure and perceived pain of a cold pressor task and a handgrip task following administration of either saline or naloxone, an opioid receptor antagonist. In the saline group there was a significant correlation between higher systolic blood pressure and lower ratings of cold pain; however, there were no significant correlations between blood pressure and ratings of the handgrip pain. No significant correlations were observed between blood pressure and pain ratings for subjects in the naloxone group for either pain test. This implies that the relationship between blood pressure and pain sensitivity may be partly mediated by endogenous opioids since the administration of naloxone abolished the relationship between blood pressure and pain sensitivity. This may mean that the relationship between blood pressure and pain sensitivity is partially mediated by the HPA-axis since $\beta$-endorphin, an 
endogenous opioid, is co-released with ACTH, an HPA-axis hormone. Taken together, these studies demonstrate a robust finding that there is a relationship between blood pressure and pain sensitivity; however, these studies were conducted only in Caucasian participants.

A handful of studies have found relationships between blood pressure and pain sensitivity in samples that include African Americans $(11,17,18)$. Unfortunately, none of these studies conducted analyses separately by ethnicity to determine if this relationship also existed in African Americans. Sheffield et al. (11) observed an inverse correlation between systolic blood pressure and pain intensity ratings of thermal stimuli but not unpleasantness ratings in a sample consisting of both African Americans and Caucasians, but the analyses were not conducted separately by ethnicity. Results in a study by Bragdon et al. (17) demonstrated a significant correlation between systolic blood pressure and thermal pain tolerance in a sample of normotensive Caucasians and African Americans, but again, analyses were not conducted separately by ethnicity. Finally, Campbell et al. (18) observed significant negative correlations between systolic blood pressure and both intensity and unpleasantness ratings to tourniquet-induced ischemia in a bi-racial normostensive sample, but analyses were not conducted separately by ethnicity. This may be important since African Americans differ in blood pressure regulatory mechanisms (19-21) such as greater vasoconstrictive responses rather than myocardial responses, which may play a role in their greater prevalence rates for hypertension (22). Thus, examination of BP-pain regulatory mechanisms separately in African Americans may have implications for ethnic differences in clinical and experimental pain. 
Related to potential ethnic differences in BP-pain sensitivity relationships, another endogenous pain regulatory factor that may differ by ethnicity involves stress-induced analgesia (SIA), a phenomenon described by decreased pain sensitivity during stress. This makes sense from an evolutionary perspective when examining a fight or flight situation. If an individual is harmed and still in a threatening situation, it is more adaptive for the person not to attend to the pain, and instead focus on removing him/herself from the dangerous situation. While SIA has been well documented in animals (see 23 for review) fewer studies have investigated SIA in humans, particularly in response to psychological stress $(17,24,25)$. Bragdon et al. (17) tested men and women for sensitivity to thermal heat pain before and after a speech stressor. Participants in each gender group were classified as either having low mean arterial pressure or high mean arterial pressure at rest. Results indicated that only in the female low mean arterial pressure group was there any evidence of SIA, since they exhibited increased pain tolerance after the speech stressor. Girdler et al. (24) tested male and female smokers and nonsmokers for sensitivity to ischemic, cold, and thermal heat pain both before and after a speech and math stressor. SIA was only observed for the sample of female nonsmokers, and only in response to the ischemic task, since ischemic pain tolerance times were higher after stress than after stress. In a study by al'Absi et al (25) participants of both sexes were randomly assigned to either a rest or stress condition. The individuals in the stress condition performed a public-speaking task while the individuals in the rest condition simply rested. Subjects then placed their hand in cold water and rated the intensity of the pain that they experienced over a 90 second time period. The participants in the stress group provided lower pain intensity ratings than the participants 
in the rest group, indicative of SIA. On the other hand, Caceres \& Burns (26) found that individuals with high mean arterial pressure reactivity showed decreases in pain tolerance after stress, indicative of stress-induced-hyperalgesia rather than SIA. Thus, while most of the studies suggest evidence for SIA, they were all conducted in primarily if not exclusively Caucasian samples, and to our knowledge, there have been no studies that have investigated the role of SIA in modulating pain perception in African Americans.

The pain modality itself may also moderate ethnic differences in pain sensitivity since different experimental pain tests have been shown to activate different endogenous pain mechanisms. When subjects were injected with either saline or naloxone, an opioid antagonist, prior to undergoing the tourniquet-induced ischemic pain procedure, those who were administered naloxone showed lower pain tolerance time relative to the saline group $(27,28)$, suggesting that pain sensitivity to the tourniquet-induced ischemia task is partially mediated by endogenous opioids. Data supporting the idea that cold pressor pain may be mediated by systemic vascular resistance comes from Girdler et al. (24) who found significant relationships between higher vascular resistance index and higher cold pressor pain tolerance, but not ischemic or thermal heat pain tolerance. Thus, sensitivity to tourniquet-induced ischemic pain involves endogenous opioid mechanisms (27-29), while sensitivity to cold pressor pain may be mediated by systemic vascular resistance (24). Most, though not all (7), of laboratory-based studies on ethnic differences in pain perception have employed only a single pain test, such as thermal heat pain $(8,9,11)$, pressure pain (10), cold pressor pain (30), or ischemic pain (1), which may limit comparisons across studies. However, Campbell, Edwards, \& Fillingim (7) found that, in response to heat, cold, and ischemic pain, African American men and women had similar 
thresholds to Caucasian men and women, but significantly lower pain tolerance to all tests. Thus, the study of Campbell et al. (7) confirms the robustness of the earlier work documenting reduced pain tolerance but not pain threshold in African Americans. These robust finding for greater pain sensitivity in African Americans to a variety of different pain tests that may differ in endogenous pain regulatory systems suggests that African Americans are more sensitive to pain and may have different pain regulatory mechanisms than Caucasians.

Catecholamines and cortisol levels may also be related to pain tolerance. Sagen et al. (31) found that increased norepinephrine levels in rats were associated with an increase pain tolerance to the tail flick and hot plate tests. Similar relationships between norepinephrine and pain tolerance have been observed in humans by Girdler et al. (24), with increased concentrations of norepinephrine are associated with increased tolerance to ischemic, cold pressor, and thermal heat pain. Additionally, the same study demonstrated that increased cortisol concentrations are associated with increased tolerance to ischemic pain (24). Similarly, al'Absi et al. (32) found that higher pain intensity ratings to the cold pressor test were related to lower cortisol concentrations, at least in men. These studies suggest that higher concentrations of catecholamines and cortisol may have analgesic effects in humans.

Consequently, the purpose of this study was to extend the work of Campbell et al. (7) by examining endogenous pain regulatory mechanisms separately in African Americans and Caucasians. Therefore, we sought to examine ethnic differences in the relationship between pain sensitivity and blood pressure, norepinephrine, cortisol, and SIA. These relationships between stress-responsive biological mechanisms (i.e. blood pressure, 
norepinephrine, cortisol) and pain sensitivity are thought to reflect an integrated response seen during the defense reaction (12), which refers to the cardiovascular and neuroendocrine changes (such as increases in blood pressure, norepinephrine and cortisol) that occur as the result of stress and are intended to prepare the body for "fight or flight." It was hypothesized that based on evidence for ethnic differences in cardiovascular and neuroendocrine responses to acute stressors that these factors would be especially relevant in examining ethnic differences in endogenous pain regulatory mechanisms. 


\section{CHAPTER 2 \\ METHODS}

Subjects: Subjects were recruited through newspaper advertisements seeking male and female nonsmokers for a study on pain perception. Of those who responded, 106 met all inclusion/exclusion criteria and constitute the subjects in this report. The subjects were composed of 50 men and 56 women, aged $18-47$ years. Approximately half $(n=51)$ of the subjects were African American (24 men, 27 women) while the other half $(n=55)$ included other ethnic groups (26 men, 29 women; 80\% Caucasian, 7\% Indian, 7\% Asian, and 5\% Hispanic). Since Indian, Asian, and Hispanic participants comprised such a small percentage of the subjects, preventing adequate power for testing effects separately in these ethnic groups, they were collapsed with the Caucasians to make up the 'Caucasian/Other' comparison group. All of the experimenters were Caucasian men or women, and no systematic effort was made to control for gender of experimenter.

All subjects were medically healthy, with no more than mildly elevated blood pressure $(<160 / 90 \mathrm{mmHg})$ as determined during an initial screening session. Only 4 subjects (2 Caucasian/Others and 2 African Americans) had elevated BP, defined as SBP > $135 \mathrm{mmHg}$ and/or DBP $>85 \mathrm{mmHg}$. Additionally, subjects were not taking any prescription medication, including oral contraceptives, and not taking any over-the-counter medication on a regular basis (e.g. nonsteroidal anti-inflammatory agents, antihistamines). All women reported regular menstrual cycles. Excluded from participating were subjects with chronic 
pain conditions (e.g. temporomandibular joint disorder, fibromyalgia, arthritis) and those exhibiting signs of depression or anxiety. Individuals with Hamilton scale (33) depression ratings greater than 7 (indicating mild depression) or anxiety ratings greater than 9 (indicating symptoms of anxiety) were excluded.

The protocol was approved by the institution's Institutional Review Board and all subjects provided informed, written consent prior to participating. Subjects received $\$ 500$ compensation.

\section{Procedures}

In order to minimize any influence that novelty of exposure to the laboratory and pain testing apparatuses would have on pain perception, during an initial screening session subjects were shown the laboratory and the pain testing equipment, subjects had the procedures described to them and then underwent a preliminary thermal pain threshold assessment. Women were tested at one of three points in their menstrual cycle (early follicular, $n=20$; late follicular, $n=20$; luteal $n=16$ ) in randomized order, with phase of cycle subsequently confirmed using serum estradiol and progesterone concentrations.

To examine decreases in pain sensitivity following mental stress compared with pain testing following rest (i.e., SIA), pain testing occurred twice; once following a modified Trier Social Stress Test (TSST) and once following a time equivalent Rest Control Period. The order of Stress versus Rest was fully counter-balanced within gender and ethnic groups.

For all subjects, lab testing began between $12 \mathrm{pm}$ and $2 \mathrm{pm}$. Immediately upon arrival, all subjects were instrumented for cardiovascular monitoring. An intravenous line (i.v.) was 
then established in an arm vein and once in place, a curtain was drawn to hide the i.v. and arm, and to minimize awareness of blood sampling.

The sequence of laboratory events was as follows: 1) Instrumentation for blood pressure and other monitoring; 2) i.v. set-up and recovery from venipuncture (10 min); 3) Baseline (10 min quiet rest); 4) Modified TSST (20 min); 5) Recovery (10 min); 6) Pain Testing; 7) Stress Testing if event \#4 was Rest Control or Rest Control if event \#4 was Stress Testing (20 min); 8) Recovery (10 min); and 9) Pain Testing. These events are described fully below.

Baseline: Immediately following the i.v. setup, 20 minutes of quiet rest followed. The first 10 minutes served as recovery from venipuncture, while the last 10 minutes constituted baseline. Blood pressures were taken at minutes 1, 3, 5, 7, and 10 and averaged to yield mean baseline rest values. Blood was sampled at minute 10 for baseline norepinephrine (NE) and cortisol.

The Trier Social Stress Test (TSST): A modified version of the TSST was employed (to include serial addition as opposed to serial subtraction). The TSST is a stress test that reliably induces large and consistent HPA and cardiovascular responses (34-36). The TSST involved the following components: 1) Pre-Task Instructions (5 min) during which time subjects are introduced to the 'selection committee' who would listen to their job talk. Subjects were also given the instructions for the mental arithmetic task; 2) Speech Preparation Period (5 min): during which time subjects were left alone to prepare their talk; 3) Job Speech (5 min): immediately following the preparation period, the selection 
committee returned to the testing room and asked the subject to deliver his/her talk describing to the committee why s/he would be the perfect applicant for the position. If the subject finished before 5 minutes, the committee responded in a standardized way, with prepared questions to ensure that the subject spoke for the entire period. Talks were taperecorded and subjects had the opportunity to earn up to $\$ 10$ based on the committee's ratings of their speech. Blood pressures were taken at minutes 1,3, and 5 of speech, and blood was sampled for plasma NE at the end of minute 2; and, 4) Paced Auditory Serial Addition Test (PASAT; 37) (8.5 min): involves the tape recorded presentation of numbers from 1-9. Subjects add each number presented on the tape to the immediately preceding number and to state the answer aloud. There are four series of numbers, with progressively shorter interdigit intervals. The experimenter remained in the room to monitor performance. Subjects had the opportunity to earn up to $\$ 10$ based upon total number of correct additions. Blood pressure was taken once each series, and blood was sampled for plasma NE at the end of minute 2 .

Stress Recovery $(10 \mathrm{~min})$ : Subjects rested quietly alone. Blood was sampled at the end of this period in order to capture the delayed plasma cortisol response to the TSST $(33,34)$.

Pain Testing Procedures: Immediately after the recovery periods that followed both the TSST and the rest control period, subjects were exposed to the three different pain tests. One of three task orders (i.e., 1- tourniquet, thermal, cold; 2- thermal, cold, tourniquet; or 3 cold, tourniquet, thermal) was randomly assigned to each subject, ensuring that equal 
numbers of men and women and African Americans and Caucasian/Others received each of the three orders.

The Submaximal Effort Tourniquet Procedure: In this procedure, as described previously (38), a tourniquet cuff was positioned on the subject's arm and the arm placed to the side. Prior to inflating the tourniquet cuff to $200 \mathrm{mmHg}$ (Hokanson E20 Rapid Cuff Inflator), the subject's arm was raised for 30 seconds to promote venous drainage, and then the cuff was inflated, the experimenter's stopwatch started, and the arm returned to the side. To promote forearm ischemia, subjects engaged in 20 handgrip exercises at 30\% of their maximum force with an inter-squeeze interval of $2 \mathrm{sec}$. Subjects were instructed to indicate when the sensations in their arm first became painful (pain threshold) and when they were no longer willing or able to tolerate the pain (pain tolerance). A maximum time limit of 20 min was enforced, though subjects were not informed of this limit.

Hand Cold Pressor: The apparatus for the cold pressor consisted of a container filled with ice and water that was maintained at $4^{\circ} \mathrm{C}$ as recorded immediately prior to initiating the test. The use of a water circulator prevented the water from warming near the subject's hand. At the onset of the test, subjects were instructed to submerge their hand to the marked line on their wrist and to remain still. Subjects were instructed to indicate to the experimenter when the sensations in their hand first became painful (pain threshold) and to also indicate when they were no longer willing or able to tolerate the pain by saying 'stop' (pain tolerance). A maximum time limit of 5 min was imposed, though subjects were not informed of this limit. 
Thermal Heat Pain Testing: Thermal heat pain threshold and tolerance were determined by an ascending method of limits using a 1-cm diameter contact thermode with the capability for a rise time of $10^{\circ} \mathrm{C} / \mathrm{sec}$. The thermode was controlled by a personal computer, and thermal probe applied to the left volar forearm. During the pain testing, an adapting temperature of $38^{\circ} \mathrm{C}$ was maintained for $10 \mathrm{sec}$. Then, the temperature increased directly to $41.5^{\circ} \mathrm{C}$ and from that point on increased $0.5^{\circ} \mathrm{C}$ every $5 \mathrm{sec}$ until it reached $53^{\circ} \mathrm{C}$ or until the subject reached his/her tolerance. To determine thermal pain onset (threshold), subjects were instructed to press a mouse button (which terminated the stimulus) when the thermal percept first became painful. This was repeated three times and averaged to calculate thermal pain thresholds. Then, three series to determine average thermal pain tolerance were conducted by instructing the subject to press a mouse button when they were no long able to tolerate the pain.

Physiological Recording Procedures: The SunTech Exercise blood pressure monitor, Model 4240 (SunTech Medical Instruments, Inc., Raleigh, NC) provided the automated measurements of BP during baseline and stress testing. Prior to initiating the baseline period, five standard stethoscopic BPs were taken simultaneously with the automated pressures to ensure correct microphone placement and cuff position.

\section{Hormone and Neuroendocrine Assays:}

Plasma cortisol was determined using radioimmunoassay (RIA) techniques (ICN Biomedical, Inc.). The sensitivity of the assay is $0.07 \mu \mathrm{g} / \mathrm{dL}$, and the specificity high, showing $0.05-2.2 \%$ cross-reactivity with most similar compounds. Plasma Norepinephrine 
concentrations were determined using the high performance liquid chromatography (HPLC) technique. The lower limit of quantification with this system is $25 \mathrm{pg} / \mathrm{ml}$, and the intra- and inter-day coefficients of variation are less than $10 \%$.

\section{Data Reduction and Analyses}

Our first analytical strategy involved comparing groups for differences that existed in demographic and baseline measures. For each dependent measure, a 2(Gender) x 2 (Ethnicity) analysis of variance (ANOVA) was employed. Next, we examined differences in pain sensitivity. Initial analyses confirmed expected gender differences in all three pain tests, with men having higher pain thresholds $($ Fs $(1,101)=9.12$ to 12.61 , ps $<.01)$ and pain tolerance $(\operatorname{Fs}(1,101)=9.37$ to $24.63, \mathrm{ps}<.01)$. Additionally, as expected, women had lower baseline and stress BP, NE, and cortisol concentrations than men $(\mathrm{Fs}(1,87)=4.48$ to 51.83 , ps $<.05)$. There were no Gender $x$ Ethnicity interactions for any dependent variable. Therefore, for analytical simplicity, gender was not considered further in the model as an independent variable. Thus, we examined differences in pain threshold and tolerance separately for each pain test, using a 2(Ethnicity) x 2(Time Point: Threshold/Tolerance) x 2(Stress/Rest) repeated measures ANOVA, with Threshold/Tolerance and Stress/Rest as

repeated factors. Where significant interactions emerged, subsequent simple effects analyses were conducted in order to explore those effects.

We then examined ethnic differences and stress effects for neuroendocrine variables. A 2(Ethnicity) x 2 or 3(Condition: Baseline, Stress; 3 time points for BP and NE, 2 time points for cortisol) ANOVA was used. As before, subsequent simple effects analyses were employed to examine significant interactions. 
In order to investigate relationships between physiological measures and pain sensitivity, a series of Pearson product moment correlational analyses were employed. To reduce Type I error rates, we focused exclusively on differences between African Americans and Caucasian/Others, collapsing across gender, and focused exclusively on baseline and the speech stressor. 


\section{CHAPTER 3 \\ RESULTS}

\section{Demographic and Baseline Characteristics}

As summarized in Table 1, the groups did not differ in age or resting heart rate, though African Americans had higher BMIs $(\mathrm{F}(1,105)=6.97, \mathrm{p}<.01)^{1}$. As expected, when compared with women, men had higher SBP $(F(1,104)=24.57, p<.0001)$ and higher DBP $(\mathrm{F}(1,104)=6.15, \mathrm{p}<.05)$

There were ethnic differences in education, since African Americans were more likely than Caucasians/Others to have attended some college but not receive a degree (18/51 vs. $\left.10 / 55 ; \chi_{(1)}^{2}=3.97, p<.05\right)$; and they were also less likely than Caucasians/Others to have done post graduate work at a university $\left(10 / 51\right.$ vs. $\left.22 / 55 ; \chi_{(1)}^{2}=5.22, p<.05\right)$. There were no ethnic differences between African Americans and Caucasians/Others in the proportion who did not complete high school (0/51 vs. 1/55), or whose highest level of education was a high school degree (3/51 vs. $1 / 55)$, trade school or business college $(2 / 51$ vs. $0 / 55)$, or a 4 year college degree (18/51 vs. 21/55).

\footnotetext{
${ }^{1}$ Pearson correlational analyses were used to examine the association of BMI to pain sensitivity. Analyses conducted separately for threshold and tolerance to each pain test failed to reveal any significant correlations involving pain sensitivity and BMI (all ps $>.10$ ).
} 


\section{Effects of Ethnicity on Pain Sensitivity}

\section{Ischemic Pain}

Threshold and Tolerance: Ischemic pain threshold and tolerance values following the rest control period (top panel) and following mental stress (bottom panel) are depicted in Figure 1. Analyses revealed a significant Time Point $x$ Ethnic interaction $(F(1,99)=13.23, p<$ .001). In order to explore this interaction, simple effects analyses were conducted separately for pain threshold and tolerance. These analyses revealed that following both stress and rest African Americans had lower pain tolerance than Caucasian/Others $(\mathrm{F}(1,102)=2.62, \mathrm{p}=$ .10), while no ethnic differences existed at threshold. There was no evidence for SIA during ischemic pain testing in either ethnic group.

\section{Cold Pain}

Threshold and Tolerance: Similar to the ischemic pain task, a Time Point x Ethnic interaction also emerged $(\mathrm{F}(1,102)=7.48, \mathrm{p}<.01)$. African Americans were more sensitive to cold pain at tolerance $(\mathrm{F}(1,103)=7.92, \mathrm{p}<.01)$ but not at threshold (see Figure 2$)$, and this was evident after both stress and rest. For neither ethnic group was there evidence of SIA during cold pain testing.

\section{Thermal Heat Pain}

Threshold and Tolerance: Similar to the ischemic and cold pain tests, there was a trend for a Time Point $\mathrm{x}$ Ethnic interaction $(\mathrm{F}(1,102)=3.44, \mathrm{p}<.07)$. African Americans had lower heat pain tolerance $(F(1,102)=5.00, p<.05)$, but not threshold (see Figure 3 ). Again, stress 
vs. rest did not influence these results. For neither ethnic group was there any evidence for SIA during thermal heat pain testing.

\section{Cardiovascular and Neuroendocrine Reactivity to Stress}

Blood Pressure: Both stressors significantly increased SBP $(\mathrm{F}(2,206)=567.26, \mathrm{p}<.0001)$ and DBP $(F(2,206)=590.17, \mathrm{p}<.0001)$ in the group as a whole. Analyses conducted separately by ethnicity indicated that SBP increased in response to stress for both Caucasians/Others $(\mathrm{F}(2,106)=301.03, \mathrm{p}<.0001)$ and African Americans $(\mathrm{F}(2,100)=$ 272.24, $\mathrm{p}<.0001)$. A significant Condition $\mathrm{x}$ Ethnic interaction was observed for SBP $(\mathrm{F}(2$, 206) $=4.56, \mathrm{p}<.05)$. While no significant differences existed between African Americans and Caucasians/Others in absolute levels of SBP at baseline (115 vs. $113 \mathrm{mmHg}$, respectively), speech stress (139 vs. $142 \mathrm{mmHg}$ ), or math stress (131 vs. $134 \mathrm{mmHg}$ ), subsequent ANOVAS comparing groups for reactivity (stress - baseline) revealed that this interaction resulted from African Americans having blunted SBP reactivity to the speech stressor (mean change $=+24 \mathrm{mmHg}$ vs. $+28 \mathrm{mmHg}$ ) relative to Caucasians/Others $(\mathrm{F}(1,105)$ $=5.54, \mathrm{p}<.05)$. There were no significant ethnic differences involving DBP.

Norepinephrine: Both stressors significantly increased plasma NE in the sample as a whole relative to baseline levels $(\mathrm{F}(2,178)=56.77, \mathrm{p}<.0001)$. Analyses conducted separately by ethnicity indicated that NE increased in response to stress for both Caucasians/Others (F(2, $98)=42.28, \mathrm{p}<.0001)$ and African Americans $(\mathrm{F}(2,80)=18.69, \mathrm{p}<.0001)$. A significant Condition $x$ Ethnic interaction was also observed for $\operatorname{NE}(F(2,178)=4.62, p<.05)$. While no significant differences existed between African Americans and Caucasians/Others in 
absolute levels of NE at baseline (182 vs. $175 \mathrm{pg} / \mathrm{mL}$, respectively), speech stress (219 vs. $243 \mathrm{pg} / \mathrm{mL}$ ), or math stress (213 vs. $220 \mathrm{pg} / \mathrm{mL}$ ), subsequent ANOVAS comparing groups for reactivity (stress - baseline) revealed that this interaction reflected blunted responses to speech (mean change $=+37 \mathrm{pg} / \mathrm{mL}$ vs. $+68 \mathrm{pg} / \mathrm{mL}$ ) and math (mean change $=+31 \mathrm{pg} / \mathrm{mL}$ vs. $+45 \mathrm{pg} / \mathrm{mL} ; \mathrm{F}(1,89)=5.38, \mathrm{p}<.05)$ in African Americans relative to Caucasians/Others.

Cortisol: Cortisol significantly increased in response to the stressors relative to baseline in the entire sample $(F(1,102)=13.75, p<.001)$. Analyses conducted separately by ethnicity indicated that there was a significant cortisol increase in response to stress for both Caucasians/Others $(F(1,54)=7.77, p<.01)$ and African Americans $(F(1,48)=6.43, p<$ .05). However, African Americans exhibited lower cortisol concentrations at both baseline ( 7.28 vs. $9.44 \mathrm{pg} / \mathrm{mL})$ and stress $(8.43$ vs. $11.01 \mathrm{pg} / \mathrm{mL})$ relative to Caucasian/Others ( $\mathrm{F}(1$, $102)=10.07, p<.01$ ), though there were no ethnic differences in cortisol reactivity (stress baseline).

\section{Perceptions of Stress:}

Following the stress tasks, participants were asked to rate each the speech and math tasks on four dimensions: 1) how difficult the task was; 2) how tense they felt during the task; 3) their ability to concentrate during the task; and 4) how much effort they put into the task. Analyses indicated that there were no ethnic differences in the ratings of dimensions listed above for the speech task $(\operatorname{Fs}(1,104)=0.38-1.37$, ps $>.10)$ or the math task $(\operatorname{Fs}(1$, 104) $=0.21-2.17$, ps $>.10)$. 


\section{Relationship of Physiological Variables to Pain Sensitivity}

Blood Pressure: As summarized in Table 2, only Caucasian/Others showed the expected positive correlations between baseline SBP and pain tolerance $(\mathrm{rs}=+.30$ to +.50 , $\mathrm{ps}<.05)$ and stress SBP and pain tolerance ( $\mathrm{rs}=+.32$ to $+.49, \mathrm{ps}<.05)$, regardless of whether testing followed stress or rest. For African Americans, there was no evidence that baseline or stress SBP related to pain sensitivity $(\mathrm{rs}=-.14$ to +.11$)$. Correlations relating SBP reactivity (speech stress-baseline) and pain tolerance values were also conducted post hoc. SBP reactivity was significantly correlated with pain tolerance in the thermal task only in the Caucasian/Others sample $(\mathrm{rs}=+.38, \mathrm{p}<.01)$, but not in the African Americans $(\mathrm{rs}=-.14$ and -.23). For neither group were any robust relationships observed involving DBP levels or reactivity and pain sensitivity .

For the significant correlations involving SBP and pain sensitivity (Table 2), group differences in the magnitude of correlation coefficients were examined using Fisher's $r$ to $z$ transformation. These analyses revealed that the correlation coefficients relating baseline SBP to pain tolerance were significantly greater in Caucasians/Others than African Americans for both the tourniquet and cold pressor tasks following rest and stress (zs= -3.4 to -1.8 , ps $<.05)$ and tended to be higher for the thermal task following rest $(\mathrm{z}=-1.3, \mathrm{p}<$ .10). The correlation coefficients relating speech stress SBP and pain tolerance were significantly greater in Caucasians/Others than African Americans for the tourniquet and thermal tasks following both rest and stress ( $\mathrm{zs}=-3.3$ to -2.5 , ps $<.01$ ), and tended to be higher for the cold pressor following both rest and stress $(\mathrm{z}=-1.4$ and -1.3 , $\mathrm{ps}<.10)$. 
Norepinephrine: There was little evidence that baseline NE correlated with pain sensitivity in either group, though African Americans showed unexpected negative and potentially spurious correlations involving baseline NE. Greater stress NE concentrations were related to higher pain tolerance to all three tests, but only in Caucasian/Others $(\mathrm{rs}=+.28$ to +.35 , ps $<.05$ ), while this relationship was absent in African Americans ( $\mathrm{rs}=-.22$ to -.11 ).

Additionally, NE reactivity to speech stress was positively correlated with pain tolerance to the cold pressor task following both rest and stress ( $\mathrm{rs}=+.34$ and +.38 , $\mathrm{ps}<.05)$, as well as thermal heat pain tolerance following rest $(\mathrm{r}=+.32, \mathrm{p}<.05)$ in Caucasian/Others, but not in African Americans ( $\mathrm{rs}=-.19$ to +.27 ).

Fisher's $r$ to $\mathrm{z}$ transformation analyses confirmed that for all three pain tasks, following rest and stress, Caucasians/Others had significantly greater correlation coefficients relating stress NE to pain tolerance $(\mathrm{z}=-2.3$ to -1.8 , $\mathrm{ps}<.05)$. Correlation coefficients relating NE reactivity to pain tolerance to the cold pressor task and thermal task were significantly larger for Caucasians/Others than African Americans $(\mathrm{z}=-2.3$ to $-1.9, \mathrm{ps}<.05)$ following both rest and stress.

Cortisol: Similar to effects seen for NE, baseline cortisol was not correlated with any pain tolerance measure for either group (see Table 2). However, greater stress cortisol levels were positively correlated with greater pain tolerance to the cold and thermal pain tests, but again this relationship was seen only in Caucasian/Others $(\mathrm{rs}=+.30$ to +.38 , $\mathrm{ps}<.05)$. No relationship between stress cortisol and pain tolerance was observed in African Americans (rs $=-.07$ to +.15$)$. In Caucasians/Others there was a significant positive correlation between cortisol reactivity to stress and pain tolerance but only during thermal heat pain following 
rest and stress $(\mathrm{r}=+.28$ to +.29 , ps $<.05)$. For the African American group there were no significant correlations between cortisol reactivity and pain tolerance ( $\mathrm{rs}=-.04$ to +.10$)$.

Although the correlations were significant in Caucasians/Others but not in African Americans, Fisher's $\mathrm{r}$ to $\mathrm{z}$ transformations failed to reveal any significant differences between Caucasians/Others and African Americans in the magnitude of the correlation coefficients relating cortisol to pain tolerance. 


\section{CHAPTER 4 \\ DISCUSSION}

The results of our study are consistent with previous findings that African Americans are more sensitive to experimental pain relative to primarily Caucasian samples (7-11), but extend these prior results by identifying potential alterations in endogenous pain regulatory mechanisms in African Americans.

For example, while numerous studies have reported an inverse relationship between SBP levels and pain sensitivity (12-17), this relationship was observed in the present study

for the primarily Caucasian group only, but not African Americans. To our knowledge there are no studies to date that have examined the relationship between BP and pain sensitivity separately in African Americans. The relationship between increased BP and reduced pain sensitivity is thought to be mediated by BP-induced stimulation of mechanoreceptive afferents (i.e. baroreceptors) since stimulation of these visceral afferents in animal models has been shown to diminish somatomotor reflexes indicative of analgesic-like effects (12, 379). It has been shown that African Americans have decreased baroresponses to transient BP elevation relative to Caucasians during sleep (40), and that they show abnormal BP responses to postural changes, indicative of alterations in baroreceptor function (41). Thus, diminished baroreceptor function in African Americans may contribute to the absence of a relationship between BP and pain sensitivity. As has been postulated for the absence of BPpain sensitivity relationships in chronic smokers, which may come about via frequent BP 
surges associated with chronic smoking (24), we speculate that larger stress-induced BP responses to real-life stress in African Americans, especially if occurring in the context of frequent stress exposure resulting from racism, poverty, crime, and/or lower SES (42) may repeatedly activate baroreceptor mechanisms and, over the long-term, contribute to a desensitization of the baroreceptor reflex pathway and an uncoupling of BP-baroreceptor mechanisms. Consequently, this might explain the apparent paradox that African Americans have a higher prevalence of hypertension (22) but at the same time they show increased sensitivity to experimental pain and more clinical pain.

An alternative, though not mutually exclusive explanation for the absence of any BPrelated hypoalgesia in African Americans, stems from our prior research documenting that plasma NE concentrations mediate the relationship between SBP and ischemic as well as cold pain tolerance in a primarily Caucasian sample of men and women (24). Thus the blunted NE stress response that we observed in the African Americans may be a contributing factor to the absence of any BP-pain sensitivity relationship in that group.

There was also a striking absence of expected relationships involving plasma NE and cortisol concentrations and pain sensitivity in the African Americans that was observed in the primarily Caucasian group; and which has also been documented in other primarily Caucasian samples $(24,32)$. Although the absence of these relationships remains unexplained at present, the blunted NE response to stress and lower cortisol concentrations at both rest and stress in the African American group may play a role. Diminished NE responses in African Americans may reflect decreased activation of locus coeruleus (LC) neurons in brain, the major site of CNS adrenergic neurons. The LC receives projections from visceral baroreceptor afferents via the nucleus of the solitary tract and is among several 
regions sending neuronal projections to spinal cord (43). Thus, the LC plays an important role in modulating sensory input. Consequently, in addition to any direct role that desensitization in baroreceptor function in African Americans may have in their hyperalgesia $(40,41)$, diminished stimulation of LC neurons and diminished activation of noradrenergic inhibitory pathways may also act to increase pain sensitivity in African Americans. This combination could account for both increased pain sensitivity and the absence of BP-pain sensitivity relationships in the African Americans.

While we observed that greater pain sensitivity in African Americans was true only for pain tolerance and not threshold, and this is consistent with other reports $(7,9)$, the reasons for this finding are currently unknown. It has been suggested that differences in tolerance reflect the affective-motivational dimensions of pain $(3,7,9,11,44)$, while differences in threshold reflect sensory-discriminative aspects (44). Thus, in addition to alterations in biological pain regulatory mechanisms, there may be ethnic differences in psychosocial factors that influence the affective motivational dimensions of the pain experience. It is well established that African Americans experience more psychosocial stress than Caucasians, including racism and bigotry (42), and experience more chronic stress, such as unemployment, poverty, lower social status, and substandard housing $(42,45)$. Thus, we hypothesize that greater chronic stress in African Americans may differentially influence affective/motivational factors that impact the experience of pain. This supposition is supported by animal models showing that chronic stress produces long-term increases in pain sensitivity to noxious stimuli (46).

Relatedly, while blunted SBP and NE reactivity to stress and lower cortisol levels seen in the African Americans in the present study may at first seem paradoxical since it has 
been shown that African Americans exhibit increased cardiovascular reactivity to laboratory stress (eg. 42), other studies have found that greater cardiovascular and NE reactivity to stressors in African Americans may reside exclusively in African American men (21, 47). Thus, the absence of greater stress reactivity in the present sample of African Americans may reflect our decision to combine the responses of men and women within ethnic groups. An alternative explanation stems from other studies documenting that individuals with higher levels of chronic stress exhibit lower levels of NE in response to acute stress (48), suggesting that chronic stress may diminish the ability of the individual to respond to new challenges (49). Therefore, the blunted SBP and NE reactivity to stress that we observed in the African Americans may be related to their higher prevalence of chronic stress, though this is a hypothesis that remains to be tested.

It is of interest that we found no evidence for SIA in any group. This cannot be explained by failure of the protocol to elicit a stress response since all subjects showed significant increases in blood pressure, NE, and cortisol in response to the stressors. The failure to observe SIA in African Americans may be related to their blunted BP and NE stress response. However, it was surprising that we did not observe SIA in the Caucasian/Other sample, especially since they showed positive correlations between stress-induced SBP, NE, and cortisol and pain tolerance following stress. One possibility for our inability to detect any evidence for SIA may be related to the time course of events. Since pain testing occurred 10-minutes after the cessation of stressors, the possibility exists that recovery of cardiovascular and neuroendocrine levels prevented us from detecting SIA. Another potential explanation is that SIA may not be a particularly robust phenomenon in humans, at least under laboratory conditions. Indeed, while some laboratory studies in humans have 
documented SIA $(17,25)$ others have found it in only subgroups of individuals $(24)$, and at least one study found that participants were more sensitive to pain following stress testing (50). Thus, future parametric research on laboratory-induced SIA in humans is indicated. In conclusion, the results of our study suggest that decreased tolerance to experimental pain in African Americans is due, in part, to alterations in endogenous pain regulatory mechanisms. As such, our results may have implications for biological mechanisms contributing to the greater rates of clinical pain in African Americans. We must acknowledge certain limitations to our study, however. The generalizability of the results may be limited by the stringent exclusionary criteria and resulting homogeneity of the study sample. This is especially true regarding the exclusion of individuals with hypertension since hypertension rates are greater in African Americans (22). Thus, our findings for altered pain regulatory mechanisms in African Americans may not generalize to a substantial subset of African Americans with hypertension. Our findings may also not generalize to African Americans with mood disturbance or chronic pain disorders, conditions for which alterations in pain sensitivity and endogenous pain regulatory mechanisms have been documented in primarily Caucasian samples $(51,52)$. Future studies designed to investigate ethnic differences in psychosocial factors and pain perception, and whether alterations in biological pain regulatory mechanisms mediate the link between greater life stress and greater pain sensitivity in African Americans are needed to further our understanding of ethnic differences in the experience of pain. 


\section{Table 1: Mean ( \pm SEM) Demographic and Baseline Characteristics as a Function of Gender and Ethnicity}

\begin{tabular}{|c|c|c|c|c|}
\hline & $\begin{array}{l}\text { African American } \\
\text { Females }(n=27)\end{array}$ & $\begin{array}{l}\text { Other Females } \\
\qquad(\mathrm{n}=29)\end{array}$ & $\begin{array}{c}\text { African American } \\
\text { Males }(n=24)\end{array}$ & $\begin{array}{l}\text { Other Males } \\
\qquad(\mathrm{n}=26)\end{array}$ \\
\hline Age (years) & $27.7(1.2)$ & $27.7(1.1)$ & $26.8(1.2)$ & $27.3(1.2)$ \\
\hline $\mathrm{BMI}^{\mathrm{A}}$ & $27.9(1.2)$ & $25.5(1.1)$ & $29.1(1.2)$ & $25.3(1.2)$ \\
\hline $\begin{array}{l}\text { Systolic Blood } \\
\text { Pressure }(\mathrm{mmHg})\end{array}$ & $111(2.0)$ & 108 (1.9) & $119(2.1)$ & $119(2.0)$ \\
\hline $\begin{array}{l}\text { Diastolic Blood }{ }^{\mathbf{B}} \\
\text { Pressure }(\mathrm{mmHg})\end{array}$ & $65(1.4)$ & $64(1.3)$ & $68(1.4)$ & $68(1.4)$ \\
\hline Heart Rate (bpm) & $68(2.0)$ & 69 (1.9) & $65(2.1)$ & $67(2.0)$ \\
\hline
\end{tabular}

A: African Americans $>$ Others, $\mathrm{p}<.05$

B: Men $>$ Women, ps $<.05$ 


\section{Table 2: Correlations between Pain Tolerance and Physiological Variables}

\begin{tabular}{|c|c|c|c|c|c|c|c|c|c|c|c|c|}
\hline & \multicolumn{2}{|c|}{$\begin{array}{l}\text { Baseline Systolic } \\
\text { Blood Pressure }\end{array}$} & \multicolumn{2}{|c|}{$\begin{array}{c}\text { Speech Stress } \\
\text { Systolic Blood Pressure }\end{array}$} & \multicolumn{2}{|c|}{$\begin{array}{c}\text { Baseline } \\
\text { Norepinephrine }\end{array}$} & \multicolumn{2}{|c|}{$\begin{array}{l}\text { Speech Stress } \\
\text { Norepinephrine }\end{array}$} & \multicolumn{2}{|c|}{ Baseline Cortisol } & \multicolumn{2}{|c|}{ Stress Cortisol } \\
\hline & AA & $\mathrm{CO}$ & AA & $\mathrm{CO}$ & AA & $\mathrm{CO}$ & AA & $\mathrm{CO}$ & AA & $\mathrm{CO}$ & AA & $\mathrm{CO}$ \\
\hline $\begin{array}{l}\text { Tourniquet } \\
\text { Tolerance } \\
\text { after Rest }\end{array}$ & $\begin{array}{l}\mathrm{r}=-.11 \\
\mathrm{p}>.40\end{array}$ & $\begin{array}{c}\mathbf{r}=+.40^{* *} \\
\mathrm{P}<.01\end{array}$ & $\begin{array}{l}r=-.05 \\
p>.70\end{array}$ & $\begin{array}{c}\mathbf{r}=+.45^{* * *} \\
\mathbf{p}<.001\end{array}$ & $\begin{array}{c}\mathbf{r}=-.33 * \\
\mathrm{p}<.05\end{array}$ & $\begin{array}{c}\mathrm{r}=+.12 \\
\mathrm{p}>.30\end{array}$ & $\begin{array}{l}r=-.14 \\
p>.30\end{array}$ & $\begin{array}{c}\mathrm{r}=+.23 \\
\mathrm{p}>.10\end{array}$ & $\begin{array}{l}\mathrm{r}=-.02 \\
\mathrm{p}>.80\end{array}$ & $\begin{array}{c}\mathrm{r}=+.05 \\
\mathrm{p}>.70\end{array}$ & $\begin{array}{l}r=-.01 \\
p>.90\end{array}$ & $\begin{array}{c}\mathrm{r}=+.13 \\
\mathrm{p}>.30\end{array}$ \\
\hline $\begin{array}{l}\text { Tourniquet } \\
\text { Tolerance } \\
\text { after Stress }\end{array}$ & $\begin{array}{l}r=-.14 \\
p>.30\end{array}$ & $\begin{array}{c}\mathbf{r}= \\
+. \mathbf{5 0} * * * \\
\mathrm{p}<.001\end{array}$ & $\begin{array}{l}\mathrm{r}=-.12 \\
\mathrm{p}>.30\end{array}$ & $\begin{array}{c}\mathbf{r}=+.49^{* * * *} \\
\mathbf{p}<.001\end{array}$ & $\begin{array}{c}\mathbf{r}=-.36^{*} \\
\mathrm{p}<.05\end{array}$ & $\begin{array}{c}\mathbf{r}=+.24 \# \\
\mathrm{p}<.10\end{array}$ & $\begin{array}{l}\mathrm{r}=-.18 \\
\mathrm{p}>.20\end{array}$ & $\begin{array}{c}\mathbf{r}=+.31 * \\
\mathrm{p}<.05\end{array}$ & $\begin{array}{l}\mathrm{r}=+.04 \\
\mathrm{p}>.70\end{array}$ & $\begin{array}{c}\mathrm{r}=+.11 \\
\mathrm{p}>.40\end{array}$ & $\begin{array}{l}r=-.07 \\
p>.60\end{array}$ & $\begin{array}{c}\mathbf{r}=+.23 \# \\
\mathrm{p}<.10\end{array}$ \\
\hline $\begin{array}{c}\text { Cold } \\
\text { Pressor } \\
\text { Tolerance } \\
\text { after Rest }\end{array}$ & $\begin{array}{c}\mathrm{r}=+.11 \\
\mathrm{p}>.40\end{array}$ & $\begin{array}{c}\mathbf{r}= \\
+. \mathbf{4 5} * * * \\
\mathrm{p}<.001\end{array}$ & $\begin{array}{l}\mathrm{r}=+.11 \\
\mathrm{p}>.40\end{array}$ & $\begin{array}{c}\mathbf{r}=+.37 * * \\
\mathbf{p}<.01\end{array}$ & $\begin{array}{l}r=-.08 \\
p>.50\end{array}$ & $\begin{array}{l}\mathrm{r}=+.18 \\
\mathrm{p}>.10\end{array}$ & $\begin{array}{l}r=-.12 \\
p>.40\end{array}$ & $\begin{array}{c}\mathbf{r}=+.35 * \\
\mathrm{p}<.05\end{array}$ & $\begin{array}{l}r=-.04 \\
p>.70\end{array}$ & $\begin{array}{c}\mathrm{r}=+.21 \\
\mathrm{p}>.10\end{array}$ & $\begin{array}{l}r=+.06 \\
p>.60\end{array}$ & $\begin{array}{c}\mathbf{r}=+.30 * \\
\mathrm{p}<.05\end{array}$ \\
\hline $\begin{array}{c}\text { Cold } \\
\text { Pressor } \\
\text { Tolerance } \\
\text { after Stress }\end{array}$ & $\begin{array}{c}\mathrm{r}=+.08 \\
\mathrm{p}>.50\end{array}$ & $\begin{array}{c}\mathrm{r}=+.41^{* *} \\
\mathrm{p}<.01\end{array}$ & $\begin{array}{c}r=+.07 \\
p>.6 r\end{array}$ & $\begin{array}{c}\mathrm{r}=+.32 \% \\
\mathrm{p}<.05\end{array}$ & $\begin{array}{l}r=-.06 \\
p>.70\end{array}$ & $\begin{array}{c}\mathrm{r}=+.13 \\
\mathrm{p}>.30\end{array}$ & $\begin{array}{l}r=-.11 \\
p>.40\end{array}$ & $\begin{array}{c}\mathbf{r}=+.33^{*} \\
\mathrm{p}<.05\end{array}$ & $\begin{array}{l}r=.00 \\
p>.90\end{array}$ & $\begin{array}{c}\mathbf{r}=+.23 \# \\
\mathrm{p}<.10\end{array}$ & $\begin{array}{c}\mathrm{r}=+.07 \\
\mathrm{p}>.60\end{array}$ & $\begin{array}{c}\mathbf{r}=+.33^{*} \\
\mathrm{p}<.05\end{array}$ \\
\hline $\begin{array}{l}\text { Thermal } \\
\text { Tolerance } \\
\text { after Rest }\end{array}$ & $\begin{array}{c}r=+.06 \\
p>.60\end{array}$ & $\begin{array}{c}\mathbf{r}=+.27 \# \\
\mathrm{p}<.06\end{array}$ & $\begin{array}{l}r=-.03 \\
p>.80\end{array}$ & $\begin{array}{c}\mathbf{r}=+.44^{* * *} \\
\mathbf{p}<.001\end{array}$ & $\begin{array}{l}r=-.07 \\
p>.60\end{array}$ & $\begin{array}{c}\mathrm{r}=+.10 \\
\mathrm{p}>.40\end{array}$ & $\begin{array}{l}r=-.17 \\
p>.20\end{array}$ & $\begin{array}{c}\mathbf{r}=+.28 \% \\
\mathrm{p}<.05\end{array}$ & $\begin{array}{c}\mathrm{r}=+.10 \\
\mathrm{p}>.50\end{array}$ & $\begin{array}{c}\mathrm{r}=+.11 \\
\mathrm{p}>.40\end{array}$ & $\begin{array}{c}\mathrm{r}=+.09 \\
\mathrm{p}>.50\end{array}$ & $\begin{array}{c}\mathbf{r}=+. \mathbf{3 8}^{* * *} \\
\mathrm{p}<.01\end{array}$ \\
\hline $\begin{array}{c}\text { Thermal } \\
\text { Tolerance } \\
\text { after Stress }\end{array}$ & $\begin{array}{c}\mathrm{r}=+.04 \\
\mathrm{p}>.70\end{array}$ & $\begin{array}{c}\mathbf{r}=+.30^{*} \\
\mathrm{p}<.05\end{array}$ & $\begin{array}{l}r=-.10 \\
p>.40\end{array}$ & $\begin{array}{c}\mathbf{r}=+.46^{* * *} \\
\mathbf{p}<.001\end{array}$ & $\begin{array}{l}r=-.11 \\
p>.40\end{array}$ & $\begin{array}{c}\mathrm{r}=+.14 \\
\mathrm{p}>.30\end{array}$ & $\begin{array}{l}r=-.22 \\
p>.10\end{array}$ & $\begin{array}{c}\mathbf{r}=+.26 \# \\
\mathrm{p}<.10\end{array}$ & $\begin{array}{c}\mathrm{r}=+.21 \\
\mathrm{p}>.10\end{array}$ & $\begin{array}{c}\mathrm{r}=+.09 \\
\mathrm{p}>.50\end{array}$ & $\begin{array}{c}\mathrm{r}=+.15 \\
\mathrm{p}>.20\end{array}$ & $\begin{array}{c}r=+.34 \% \\
p<.05\end{array}$ \\
\hline
\end{tabular}




\section{Figure 1: Ischemic Pain Sensitivity After Rest}
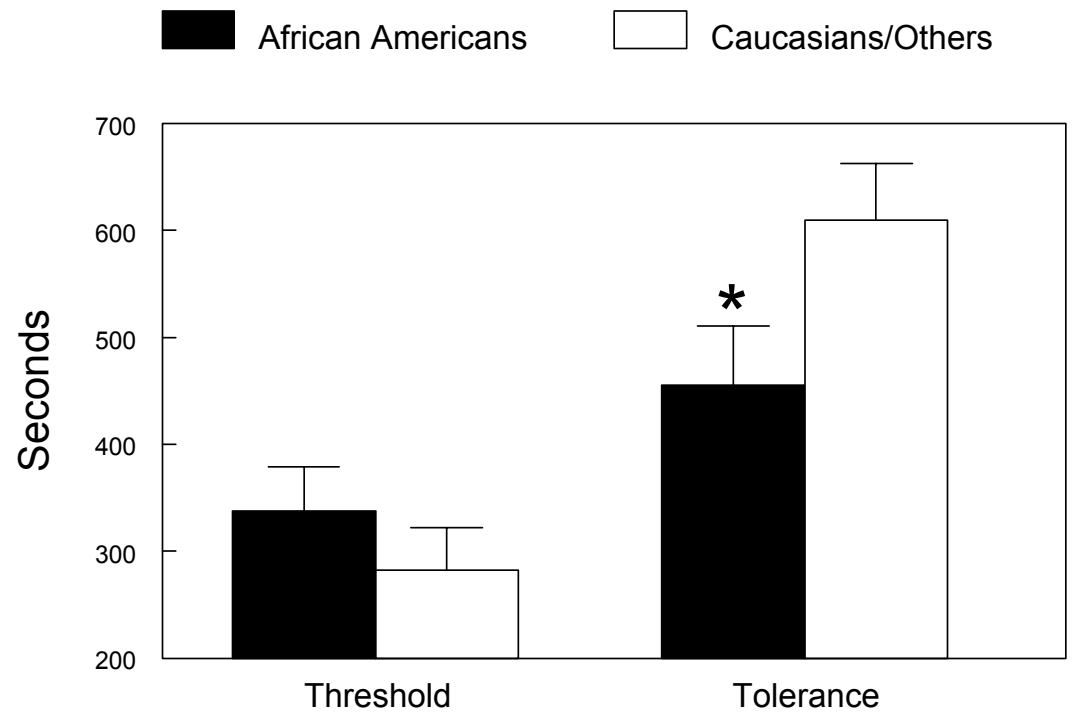

\section{Ischemic Pain Sensitivity \\ After Stress}
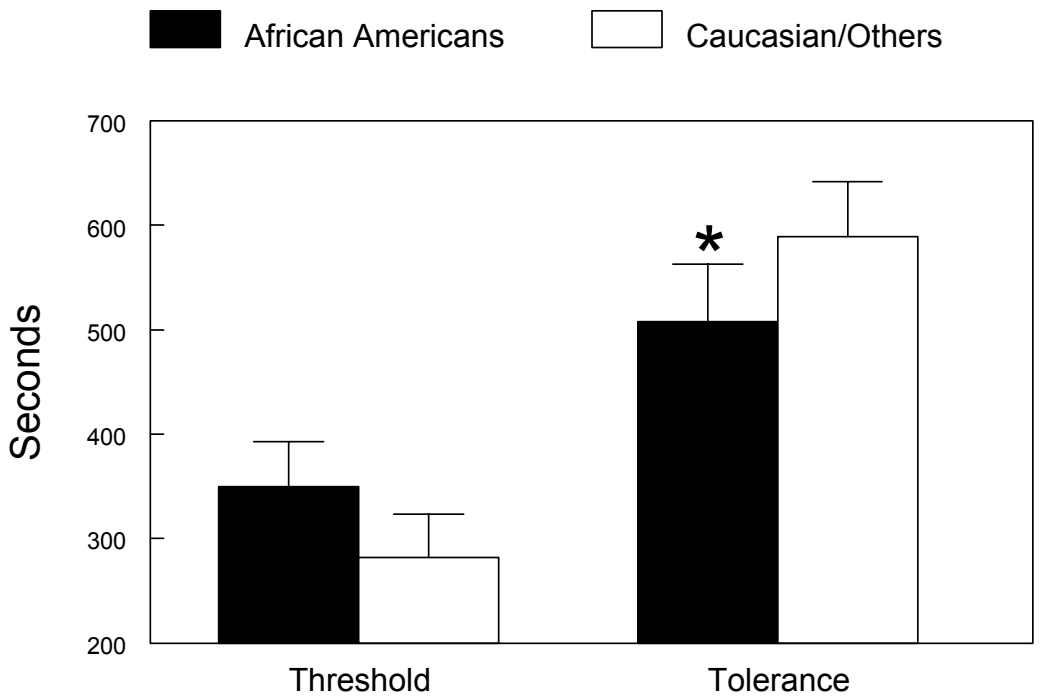

Figure 1: Mean (+ SEM) ischemic pain threshold and tolerance levels as a function of ethnicity and rest versus stress conditions. African Americans had significantly lower tolerance values after rest and stress, while no ethnic differences existed in threshold levels (Time Point $\mathrm{x}$ Ethnic interaction, ${ }^{*} \mathrm{p}<.001$ ) 


\section{Figure 2: Cold Pain Sensitivity}

After Rest

African Americans

Caucasian/Others

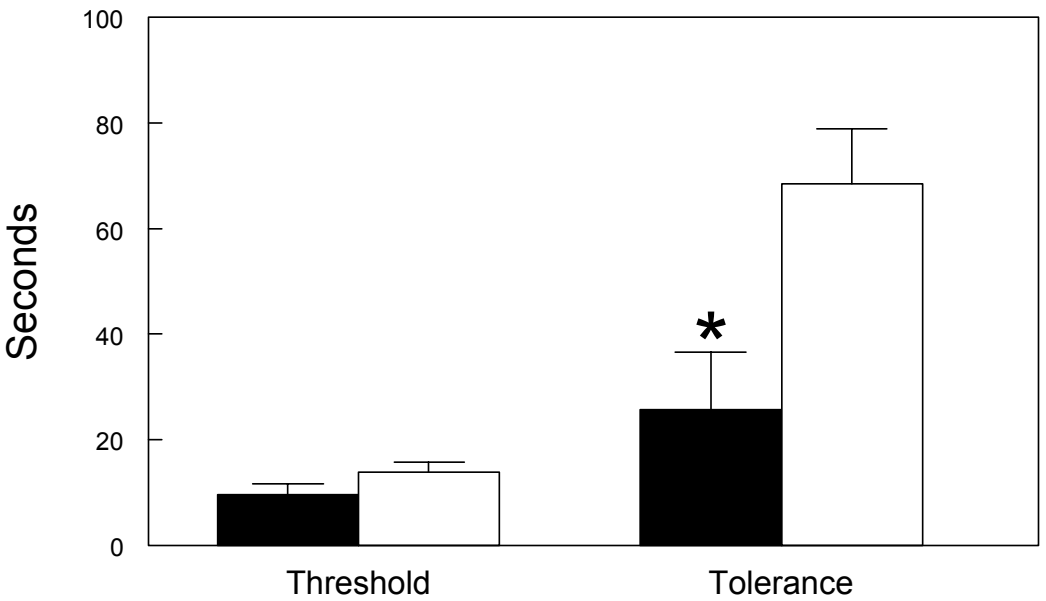

Cold Pain Sensitivity

After Stress

African Americans $\square$ Caucasian/Others

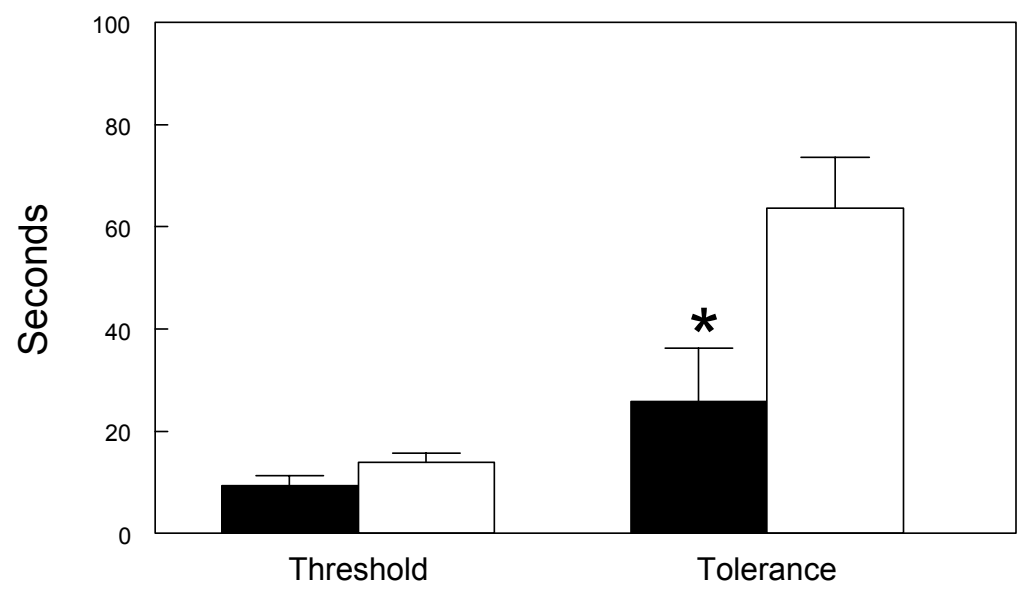

Figure 2: Mean (+ SEM) cold pain threshold and tolerance levels as a function of ethnicity and rest versus stress conditions. African Americans had significantly lower tolerance values after rest and stress, while no ethnic differences existed in threshold levels (Time Point $\mathrm{x}$ Ethnic interaction, $* \mathrm{p}<.01)$. 
Figure 3: Thermal Pain Sensitivity

After Rest

African Americans $\square$ Caucasian/Others

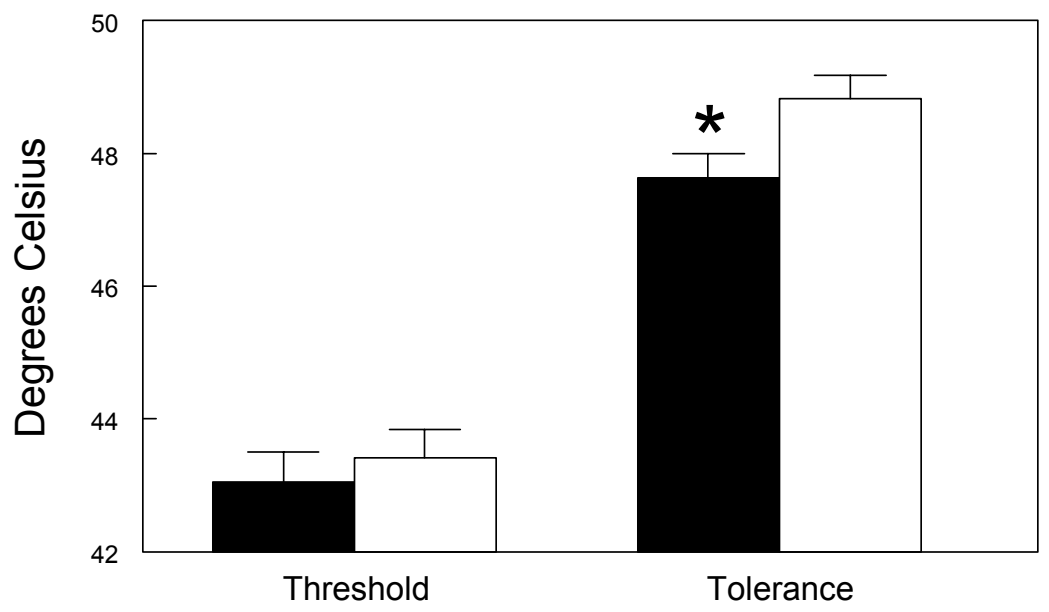

Thermal Pain Sensitivity

After Stress

African Americans $\square$ Caucasian/Others

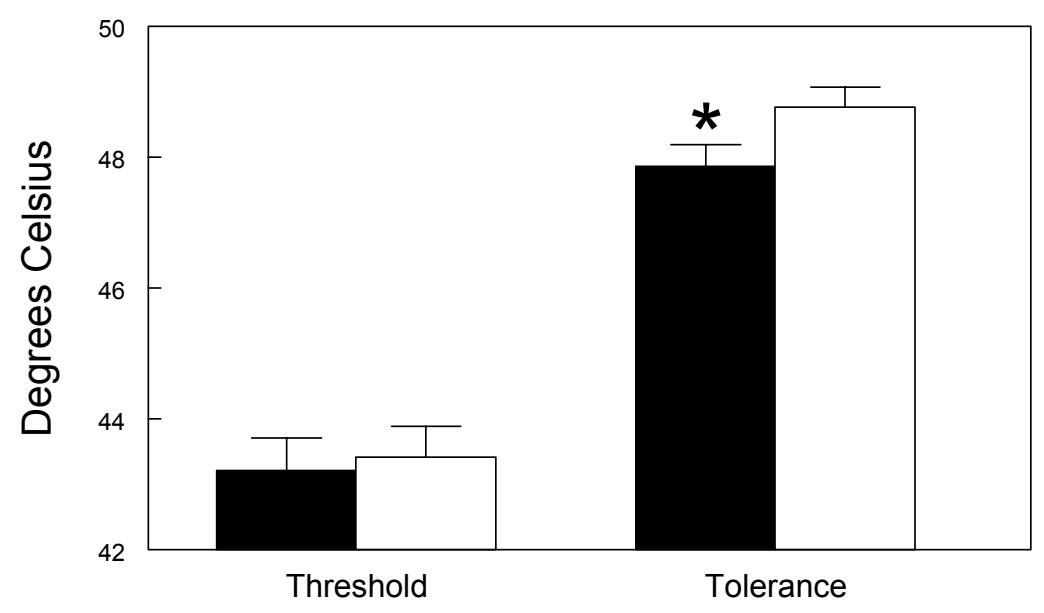

Figure 3: Mean (+ SEM) thermal heat pain threshold and tolerance levels as a function of ethnicity and rest versus stress conditions. African Americans tended toward lower tolerance values after rest and stress, while no ethnic differences existed in threshold levels (Time Point $\mathrm{x}$ Ethnic interaction, $* \mathrm{p}<.07)$. 


\section{REFERENCES}

1. Edwards RR, Doleys DM, Fillingim RB, Lowery D. Ethnic differences in pain tolerance: Clinical implications in a chronic pain population. Psychosom Med 2001; 63: 316-323.

2. McCracken LM, Matthews AK, Tang TS, Cuba SL. A comparison of blacks and whites seeking treatment for chronic pain. Clin J Pain 2001; 17: 249-255.

3. Riley JL 3rd, Wade JB, Myers CD, Sheffield D, Papas RK, Price DD. Racial/ethnic differences in the experience of chronic pain. Pain 2002; 100: 291-298.

4. Edwards CL, Fillingim RB, Keefe, F. Race, ethnicity and pain. Pain 2001; 94: 133-137.

5. Fillingim RB, Maixner W, Kincaid S, Sigurdsson A, Harris MB. Pain sensitivity in patients with temporomandibular disorders: relationship to clinical and psychosocial factors. Clin J Pain 1996; 12: 260-269.

6. Diatachenko L, Slade GD, Nackley AG, Bhalang K, Sigurdsson A, Belfer I, Goldman D, Xu K, Shabalina SA, Shagin D, Max MB, Makarov SS, Maixner W. Genetic basis for individual variations in pain perception and the development of a chronic pain condition. Hum Mol Genet 2005; 14(1): 135 - 143.

7. Campbell CM, Edwards RR, Fillingim RB. Ethnic differences in response to multiple experimental pain stimuli. Pain 2005; 113:20-26.

8. Chapman WP, Jones CM. Variations in cutaneous and visceral pain sensitivity in normal subjects. J Clin Invest 1944; 23: 81-91.

9. Edwards RR, Fillingim RB. Ethnic differences in thermal pain responses. Psychosom Med 1999; 61: 346-354.

10. Woodrow KM, Friedman GD, Siegelaub AB, Collen MF. Pain tolerance: Differences according to age, sex and race. Psychsom Med 1972; 34: 548-556.

11. Sheffield D, Biles PL, Orom H, Maixner W, Sheps DS. Race and sex differences in cutaneous pain perception. Psychosom Med 2000; 62: 517-523.

12. Maixner W. Interactions between cardiovascular and pain modulatory systems: Physiological and pathophysiological implications. J Cardiovasc Electrophysiol 1991; 2: S3-S12.

13. Zamir N, Shuber E. Altered pain perception in hypertensive humans. Brain Res 1980; 201: 471-474. 
14. Sheps DS, Bragdon EE, Gray TF 3rd, Ballenger M, Usedom JE, Maixner M. Relation between systemic hypertension and pain perception. Am J Cardio 1992; 70: F3-F5.

15. Bruehl S, Carlson CR, McCubbin JA. The relationship between pain sensitivity and blood pressure in normotensives. Pain 1992; 48: 463 - 467.

16. McCubbin JA, Bruehl S. Do endogenous opioids mediate the relationship between blood pressure and pain sensitivity in normotensives? Pain 1994; 57: 63-67.

17. Bragdon EE, Light KC, Girdler SS, Maixner W. Blood Pressure, gender, and parental hypertension are factors in baseline and poststress pain sensitivity in normotensive adults. Int J Behav Med 1997; 4: 17-38.

18. Campbell TS, Hughes JW, Girdler SS, Maixner W, Sherwood A. Relationship of ethnicity, gender, and ambulatory blood pressure to pain sensitivity: Effects of individualized pain rating scales. J Pain 2004; 5: 183-191.

19. Girdler SS, Hinderliter AL, Light KC. Peripheral adrenergic receptor contributions to cardiovascular reactivity: Influence of race and gender. J Psychosom Res 1993; 37: 177193.

20. Sherwood A, Hinderliter AL. Responsiveness to $\alpha$ - and $\beta$-adrenergic receptor agonists: Effects of race in borderline hypertensive compared to normotensive men. Am J Hypertens 1993; 6: 630-635.

21. Light KC, Turner JR, Hinderliter AL, Sherwood A. Race and gender comparisons: I. hemodynamic responses to a series of stressors. Health Psychol 1993; 12: 354-365.

22. American Heart Association. Heart Disease and Stroke Statistics - 2005 Update. Dallas: American Heart Association; 2004.

23. Watkins LR, Mayer DJ. Multiple endogenous opiate and non-opiate analgesia systems: Evidence of their existence and clinical implications. Ann NY Acad Sci 1986:467:273299.

24. Girdler SS, Maixner W, Naftel HA, Stewart PW, Moretz RL, Light KC. Cigarette smoking, stress-induced analgesia and pain perception in men and women. Pain 2005; 114: 372-385.

25. al'Absi M, Petersen KL. Blood pressure but not cortisol mediates stress effects on subsequent pain perception in healthy men and women. Pain 2003; 106: 285-295.

26. Caceres C, Burns JW. Cardiovascular reactivity to psychological stress may enhance subsequent pain sensitivity. Pain 1997; 69: $237-244$.

27. Frid M, Singer G, Rana C. Interactions between personal expectations and naloxone: Effects on tolerance to ischemic pain. Psychopharmacology 1979; 65: 223-231. 
28. Frid M, Singer G, Oei T, Rana C. Reactions to Ischemic Pain: Interactions between individual, situational, and naloxone effects. Psychopharmacoloyg 1981; 73: $116-119$.

29. Schull J, Kaplan H, O'Brien CP. Naloxone can alter experimental pain and mood in humans. Physiol Psychol 1981; 9: 245-251.

30. Walsh NE, Schoenfeld L, Ramamurthy S, Hoffman J. Normative model for cold pressor test. Am J Phys Med Rehabil 1989; 68: 6-11.

31. Sagen J, Kemmler JE, Wang H. Adrenal medullary transplants increase spinal cord cerebrospinal fluid catecholamine levels and reduce pain sensitivity. J Neurochem 1991; 56: 623-627.

32. al'Absi M, Petersen KL, Wittmers LE. Adrenocortical and hemodynamic predictors of pain perception in men and women. Pain 2002; 96: 197-204.

33. Williams JB. A structured interview guide for the Hamilton depression rating scale. Arch Gen Psychiatry 1988; 45: 742-747.

34. Kirschbaum C, Pirke KM, Hellhammer DH. The 'Trier Social Stress Test' - a tool for investigating psychobiological stress responses in a laboratory setting. Neuropsychobiology 1993; 28: 76-81.

35. Kirshbaum C, Klauer T, Filipp SH, Hellhammer DH. Sex-specific effects of social support on cortisol and subjective response to acute psychological stress. Psychsom Med 1995; 57: 23-31.

36. Kirschbaum C, Prussner JC, Stone AA, Federenko I, Gaab J, Lintz D, Schommer N, Hellhammer DH. Persistent high cortisol responses to repeated psychological stress in a subpopulation of healthy men. Psychsom Med 1995; 57: 468-474.

37. Gronwall DMA. Paced auditory serial-addition task: a measure of recovery from concussion. Percept Motor Skills 1977; 44: 367-373.

38. Maixner W, Gracely RH, Zuniga JR, Humphrey CB, Bloodworth GR. Cardiovascular and sensory responses to forearm ischemia and dynamic hand exercise. Am J Physiol 1990; 259: R1156-R1163.

39. Randich A, Maixner W. The role of sinoaortic and cardiopulmonary baroreceptor reflex arcs in nociception and stress-induced analgesia. Ann NY Acad Sci 1986; 467: 385-401.

40. Crisostomo I, Zayyad A, Carley DW, Abubaker J, Önal E, Stepanski EJ, Lopata M, Basner RC. Chemo- and baroresponses differ in African-Americans and Caucasians in sleep. J Appl Physiol 1998; 85: 1413-1420. 
41. Goldstein IB, Shapiro D. The cardiovascular response to postural change as a function of race. Biol Psychol 1995; 39: 173-186.

42. Andersen NB, McNeilly M, Myers H. Toward understanding race differences in autonomic reactivity: a proposed contextual model. In: Turner JR, Sherwood A, Light $\mathrm{KC}$, editors. Individual differences in cardiovascular response to stress. New York: Plenum Press; 1992; p.125-145.

43. Maixner W. Autonomic and somatosensory interactions: Physiological and pathophysiological implications. Proc Finn Dent Soc 1989; 85: 395-407.

44. Price DD. Psychophysical measurement of normal and abnormal pain processing. In: Boivie J, Hansson, P, Lindblom U, editors. Touch, temperature, and pain in health and disease. mechanisms and assessments, progress in pain research and management. vol. 3. Seattle: IASP Press; 1994. p. 3-25.

45. Troxel WM, Matthews KA, Bromberger JT, Sutton-Tyrell K. Chronic stress burden, discrimination, and subclinical carotid artery disease in African American and Caucasian women. Health Psychology 2003; 22: 300-309.

46. Quintero L, Moreno M, Avila C, Arcaya J, Maixner W, Suarez-Roca H. Long-lasting delayed hyperalgesia after subchronic swim stress. Pharmacol Biochem Behav 2000; 67: 449-458.

47. Light KC, Turner JR, Hinderliter AL, Girdler SS, Sherwood A. Comparison of cardiac versus vascular reactors and ethnic groups in plasma epinephrine and norepinephrine responses to stress. Int J Behav Med 1994; 1: 229-246.

48. Matthews KA, Gump BB, Owens JF. Chronic stress influences cardiovascular and neuroendocrine responses during acute stress and recovery, especially in men. Health Psychol 2001; 20: 403-410.

49. McEwen BS. Protective and damaging effects of stress mediators. N Engl J Med 1998; 338: 171-179.

50. Caceres C, Burns JW. Cardiovascular reactivity to psychological stress may enhance subsequent pain sensitivity. Pain 1997; 69: 237-244.

51. Maixner W, Fillingim R, Kincaid S, Sigurdsson A, Odont C, Harris MB. Relationship between pain sensitivity and resting arterial blood pressure in patients with painful temporomandibular disorders. Psychsom Med 1997; 59: 503-511.

52. Dickens $\mathrm{C}, \mathrm{McGowan} \mathrm{L}$, Dale S. Impact of depression on experimental pain perception: A systemic review of the literature with meta-analysis. Psychsom Med 2003; 65: 369375. 